\title{
IDENTIFICATION BY SSR AND SRAP MARKERS AND HETEROSIS ANALYSIS OF F1 HYBRIDS (Medicago ruthenica L.)
}

\author{
Yanting YANG, Rui GU, Jiaqi DONG, Yutong ZHANG, Fengling SHI*, Fang TANG* \\ Inner Mongolia Agricultural University, College of Grassland, Resources and Environment, Key \\ Laboratory of Grassland Resources of the Ministry of Education, Inner Mongolia, CHINA \\ *Corresponding author: nmczysfl@126.com,tangfang0401@hotmail.com
}

Received: 30.09.2020

\begin{abstract}
Medicago ruthenica $L$. could be used as the crossbreeding material in forage crops to provide rich resistance gene resources based on its strong resistance to adversity stress. This study aimed to identify the authenticity and analyze heterosis of the intraspecific hybrids acquired from two Medicago ruthenica L. materials. The results showed 85 true hybrids in 118 F1 progenies identified by one SSR marker and five SRAP markers. Besides, the SRAP markers $(\mathbf{1 3 . 8 9 \% )}$ ) indicated higher identification efficiency than SSR markers (7.69\%), and the rate of true hybrids in $\mathrm{HZ}$ population $(100 \%)$ was higher than that in $\mathrm{ZH}$ population (36.54\%). The six agronomic traits varied to different degrees, and their variation coefficients ranged from $18.53 \%$ to $45.72 \%$ in 13 hybrids of $\mathrm{ZH}$ population in 2019 and 2020. Moreover, ZH7 and ZH8 presented excellent agronomic performance, which could be used as candidate materials for further research. The mid-parent heterosis $(\mathrm{Hm})$ of all agronomic traits was between $\mathbf{- 2 0 . 5 5 \%}$ and $36.46 \%$, and heterobeltiosis (Hh) showed negative values of 13 hybrids.
\end{abstract}

Key words: Heterosis, intraspecific hybridization, Medicago ruthenica L., molecular marker

\section{INTRODUCTION}

Medicago ruthenica $L$. is a perennial forage in the Medicago family. It has a wide distribution in the grassland of Siberia, Mongolia, and northern China, due to its remarkable ability to resist cold and drought under unfavorable environmental conditions (Campbell et al., 1997). It is of great significance to maintain grassland health and realize the sustainable development of grassland. However, it is urgent to breed high yield and good quality cultivars of Medicago forage from Medicago ruthenica L., which could provide abundant and diverse genetic resources.

Crossbreeding is an effective method to screen the offspring with excellent performance. The morphological characteristics, such as plant height, seed size, and leaf length, have rich genetic diversity in different Medicago ruthenica L. resources (Shi et al., 2009; Li et al., 2012), which has the potential advantages for breeding and domesticating cultivated varieties. Due to its strong resistance to abiotic stress, Medicago ruthenica L. and Medicago sativa L. 'zhaodong' were used as parents to obtain Medicago sativa L. 'Longmu 801' with strong cold resistance (Liu et al., 2015), disease resistance (Ma et al., 2017), and drought resistance(Liu et al., 2009). However, the intraspecific hybridization research was limited in
Medicago ruthenica L., and studies on agronomic traits performance needed to be strengthened in their hybrids.

Identifying hybrids is a primary and necessary concern in developing conservation and management strategies after crossbreeding. Besides, it is essential to verify the accuracy of hybrids at the molecular level, especially for the hybrids obtained from intraspecific hybridization. It has been developed different kinds of molecular markers to identify hybrids, such as RAPD (Random Amplification Polymorphic DNA) (Hashemi et al., 2009), SSR (Simple Sequence Repeat) (Saxena et al., 2010), and other DNA markers based on sequencing (Du et al., 2010; Havelka et al., 2017). Sequence Related Amplified Polymorphism (SRAP) has the advantages of good repeatability, high polymorphism, and uniform distribution in the genome, which has been widely used in various research, including genetic diversity (Guenni et al., 2016; Zheng et al., 2017), construction of a genetic map (Liang et al., 2015), DNA fingerprinting analysis (Qi et al., 2010), as well as hybrids identification.

The phenomenon of heterosis has proved to be an important genetic tool in evaluating agronomic traits of hybrids (Patel et al., 2012). Heterosis analysis has been widely reported in alfalfa breeding studies to improve their production and quality. (Xue et al., 2015; Cai et al., 2013). Medicago ruthenica L. Sojak 'zhilixing' is a cultivar with 
strong resistance, good feeding value and high yield (Shu et al., 2018; Campbell and Xia, 2002; Li, 2007), which has been introduced to the alpine region. Compared with the wild Medicago ruthenica L., Medicago ruthenica L. Sojak 'zhilixing' has a relatively high forage yield. And there were differences in their plant natural height, leaf length, and flower color. The current study developed the noncastration hybridization and acquired F1 hybrid populations from crossing Medicago ruthenica L. Sojak 'zhilixing' with wild Medicago ruthenica L.. We determined the authenticity of hybrids and analyzed their agronomic traits growth in the first and second years. The results of their agronomic traits could guide agricultural production, and some hybrids could be selected as candidate materials for future molecular breeding, genetic map construction, and QTL mapping.

\section{MATERIALS AND METHODS}

\section{Plant material}

The F1 hybrid populations were named as $\mathrm{ZH}$ population (Medicago ruthenica L. Sojak 'zhilixing' $q \times$ wild Medicago ruthenica L. ${ }^{\top}$ ) and $\mathrm{HZ}$ population (wild Medicago ruthenica L. $+\times$ Medicago ruthenica L. Sojak 'zhilixing' §), which included 52 individuals and 66 individuals, respectively. The parents grew in an experimental field in Hohhot, China (Figure 1). Hohhot (Latitude $40^{\circ} 83^{\prime}$ and Longitude $111^{\circ} 73^{\prime}$ ) is located in the central part of Inner Mongolia and dominated by a temperate continental monsoon climate. The pollination was performed at 9:00 11:00 a.m. during the blossoming period in 2017 and 2018. After removing the unhealthy florets of female parent, three florets were retained for pollination without emasculation. The pollinated flowers were covered with thin cottons for defensive and protective functions. The cottons were removed on the next day, and the seeds were harvested when they were ripe.

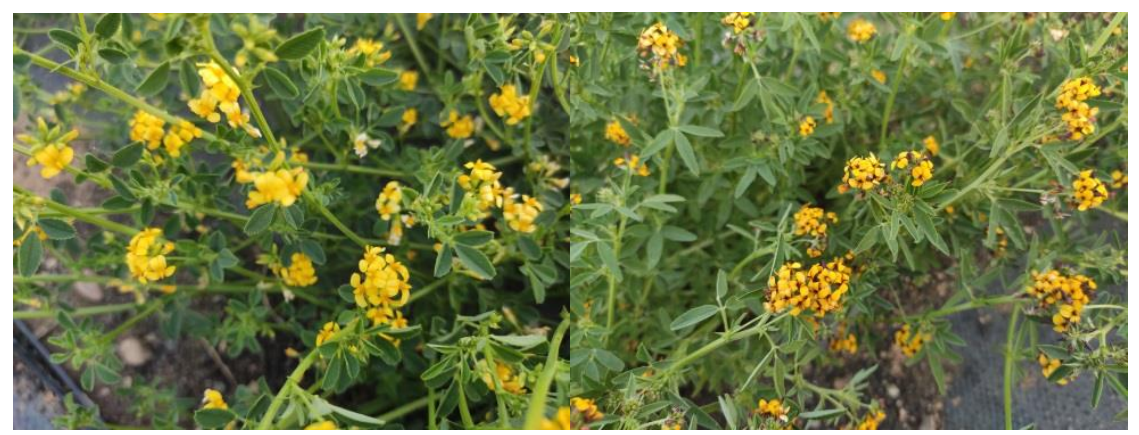

Figure 1. The photos of hybrid parents

Note: The left is wild Medicago ruthenica L., and the right is Medicago ruthenica L. Sojak 'zhilixing'.

The HZ population was planted in pots in April 2018 and transplanted into an experimental field in July 2018. The parents and $\mathrm{ZH}$ population were planted in pots in April 2019 and transplanted into a different experimental field in July 2019. Each individual was spaced $50 \mathrm{~cm}$ apart from others. The leaves of parents and F1 populations were used for molecular identification, and the true hybrids of $\mathrm{ZH}$ population and parents were used to determine of agronomic traits.

\section{DNA extraction and detection}

The total genomic DNA was extracted by using plant genomic DNA kit DP305 (TianGen Biotech, Beijing) following the manufacturer's instructions. DNA concentration was determined by NanoDrop 2000. DNA integrity was evaluated by agarose gel electrophoresis. The DNA samples were diluted to $40 \mathrm{ng} \mu \mathrm{L}-1$ and stored at $20^{\circ} \mathrm{C}$.

\section{SSR analysis}

Thirteen pairs of primers were used for SSR analysis (Table 1). The PCR reaction was $20 \mu \mathrm{L}$ containing $1 \mu \mathrm{L}$ DNA, $1 \mu \mathrm{L}$ forward primer $(10 \mu \mathrm{M}), 1 \mu \mathrm{L}$ reverse primer $(10 \mu \mathrm{M}), 10 \mu \mathrm{L} 2 \times$ Taq PCR MasterMix (TianGen Biotech, Beijing), and $7 \mu \mathrm{L}$ ddH2O. PCR was performed by 2720 thermal cycler (Applied Biosystems, USA) and programmed for initial denaturation of $2 \mathrm{~min}$ at $94^{\circ} \mathrm{C} ; 30$ cycles of $45 \mathrm{~s}$ of denaturing at $94^{\circ} \mathrm{C}, 40 \mathrm{~s}$ of annealing at the specific annealing temperature, and $45 \mathrm{~s}$ of elongation at $72^{\circ} \mathrm{C}$; final extension at $72^{\circ} \mathrm{Cfor} 7 \mathrm{~min}$ (Wu et al., 2015; Wang et al., 2016). The PCR products were fractionated by electrophoresis on $8 \%$ polyacrylamide gel in $1 \times \mathrm{TBE}$ buffer at $12.5 \mathrm{~V} \mathrm{~cm}-1$ for $1.5 \mathrm{~h}$ and stained with AgNO3 (Bassam et al., 1991; Talebi et al., 2011). 
Table 1. SSR primer information

\begin{tabular}{|c|c|c|c|}
\hline \multirow{2}{*}{$\begin{array}{l}\text { Primer } \\
\text { name }\end{array}$} & \multicolumn{2}{|c|}{ Primer sequence (5'to3') } & \multirow{2}{*}{$\begin{array}{l}\text { Annealing } \\
\text { temperature }\end{array}$} \\
\hline & Forward sequence & Reverse sequence & \\
\hline W6018 & AGC AGG ATT TGG GAC AGT TGT & ACC GTA GCT CCC TTT TCC A & $55^{\circ} \mathrm{C}$ \\
\hline Alf1 & CTT GGA ACT ATT GTT GAG T & ACC GTT TCC CAA AAC ATA CTT & $50^{\circ} \mathrm{C}$ \\
\hline Alf4 & GGG GAT TCT TGA ATA GAT G & TGG TTC GCT GTT CTC ATG & $50^{\circ} \mathrm{C}$ \\
\hline A1f2 & TTT TCC CAC CTC ATT AG & TTG AGA TTC AAA GGG TTA C & $46^{\circ} \mathrm{C}$ \\
\hline A1f3 & CCC ATC AAC ATT TTC A & TTG ATT GGA ACG AGT & $43.2^{\circ} \mathrm{C}$ \\
\hline W6002 & CAT ATT GTT AGA TTT GTG G & GTG AGC GTT AAG TTG GTA GAG & $45^{\circ} \mathrm{C}$ \\
\hline W6007 & $\begin{array}{c}\text { GAT TTG GGC CTC ATT CCT TCT } \\
\text { TGT }\end{array}$ & $\begin{array}{c}\text { CCT GAA GGG GGA AAA TTG CCC } \\
\text { AC }\end{array}$ & $58^{\circ} \mathrm{C}$ \\
\hline W6019 & TGG AAT TTG GGA TAT AGG AAG & GCC ATA AGA ACT TCC ACT T & $49.2^{\circ} \mathrm{C}$ \\
\hline AFca1 & CGT ATC AAT ATC GGG CAG & TGT TAT CAG AGA GAG AAA GCG & $51^{\circ} \mathrm{C}$ \\
\hline AFca11 & CTT GAG GGA ACT ATT GTT GAG T & AAC GTT TCC CAA AAC ATA CTT & $52^{\circ} \mathrm{C}$ \\
\hline MTR58 & GAA GTG GAA ATG GGA AAC C & GAG TGA GTG AGT GTA AGA GTG C & $52^{\circ} \mathrm{C}$ \\
\hline AFctt1 & CCC ATC ATC AAC ATT TTC A & TTG TGG ATT GGA ACG AGT & $49.5^{\circ} \mathrm{C}$ \\
\hline MTLEC2A & $\begin{array}{l}\text { CGG AAA GAT TCT TGA ATA GAT } \\
\text { G }\end{array}$ & TGG TTC GCT GTT CTC ATG & $50^{\circ} \mathrm{C}$ \\
\hline
\end{tabular}

\section{SRAP analysis}

Six forward primers and six reverse primers were paired randomly for a total of 36 combinations for SRAP analysis (Table 2, Table 3) (Devran and Baysal, 2012). The PCR reaction was the same as that in the SSR analysis. The PCR was carried out with the following conditions: initial denaturation at $94^{\circ} \mathrm{C}$ for $10 \mathrm{~min} ; 5$ cycles of $1 \mathrm{~min}$ of denaturing at $94^{\circ} \mathrm{C}, 1 \mathrm{~min}$ of annealing at $35^{\circ} \mathrm{C}$ and $2 \mathrm{~min}$ of elongation at $72^{\circ} \mathrm{C} ; 30$ cycles with annealing temperature at $50^{\circ} \mathrm{C}$; elongation at $72^{\circ} \mathrm{C}$ for $7 \mathrm{~min}$. The PCR products were followed the same procedure as above SSR analysis.

Table 2. Information of SRAP primer

\begin{tabular}{cccc}
\hline Forward primer & Sequence(5'to3') & Reverse primer & Sequence(5'to3') \\
\hline F1 & TGAGTCCAAACCGGAGC & R1 & GACTGCGTACGAATTTGC \\
F2 & CGAATCTTAGCCGGCAC & R2 & GACTGCGTACGAATTAAC \\
F3 & CGAATCTTAGCCGGAAT & R3 & GACACCGTACGAATTGAC \\
F4 & GTAGCACAAGCCGGAGC & R4 & GACACCGTACGAATTTGA \\
F5 & CGAATCTTAGCCGGATA & R5 & CGCACGTCCGTAATTCCA \\
F6 & TGAGTCCAAACCGGATA & R6 & GACTGCGTACGAATTAAT \\
\hline
\end{tabular}

Table 3. Information of SRAP combinations

\begin{tabular}{cccccc}
\hline Primer number Primer combination & Primer number & Primer combination & Primer number & Primer combination \\
\hline FR1 & F1R1 & FR13 & F1R5 & FR25 & F5R5 \\
FR2 & F1R2 & FR14 & F2R5 & FR26 & F6R1 \\
FR3 & F1R3 & FR15 & F3R5 & FR27 & F6R2 \\
FR4 & F1R4 & FR16 & F4R1 & FR28 & F6R3 \\
FR5 & F2R1 & FR17 & F4R2 & FR29 & F6R4 \\
FR6 & F2R2 & FR18 & F4R3 & FR30 & F6R5 \\
FR7 & F2R3 & FR19 & F4R4 & FR31 & F1R6 \\
FR8 & F2R4 & FR20 & F4R5 & FR32 & F2R6 \\
FR9 & F3R1 & FR21 & F5R1 & FR33 & F3R6 \\
FR10 & F3R2 & FR22 & F5R2 & FR34 & F4R6 \\
FR11 & F3R3 & FR23 & F5R3 & FR36 & F5R6 \\
FR12 & F3R4 & FR24 & F5R4 & & F6R6 \\
\hline
\end{tabular}

\section{Agronomic traits analysis}

The plant absolute height, natural height, number of primary branches, leaf length, leaf width, and plant aboveground biomass of parents and $13 \mathrm{~F} 1$ hybrids in $\mathrm{ZH}$ population were measured in September 2019 and June 2020, respectively. Approximate leaf area was the product of leaf length and width. Plant type index was the ratio of plant natural height to absolute height. Variation coefficient (\%) was the ratio of standard deviation to mean value. Five 
biological replicates were randomly selected in parents. The temperature information was shown in Table 4 at growing periods in 2019 and 2020. All the materials were consistent in field management.

\section{Data analysis}

EXCEL 2007 was used for heterosis analysis. Midparent heterosis $(\mathrm{Hm})$ was determined based on percent increase or decrease of mean value in hybrids against their mid-parent value. $\mathrm{Hm}=(\mathrm{F} 1-\mathrm{MP}) / \mathrm{MP} \times 100 \%$, where $\mathrm{MP}$ was the mid-parent value. Heterobeltiosis (Hh) was calculated based on percent increase or decrease of mean value in hybrids over their better parent value (Abro et al., 2009). $\mathrm{Hh}=(\mathrm{F} 1-\mathrm{BP}) / \mathrm{BP} \times 100 \%$, where $\mathrm{BP}$ was the better parent value.

\section{RESULTS AND DISCUSSION}

\section{Screening of molecular markers and identification of F1 populations}

Six molecular markers were selected with different loci in parents (Figure 2), including Alf3, which was screened from 13 SSR markers, and FR4, FR9, FR25, FR28, as well as FR36 which were screened from 36 SRAP combinations. The identification efficiency of SRAP combinations $(13.89 \%)$ was higher than SSR markers (7.69\%). When hybrids had the specific locus of male parent, they could be identified as true hybrids (Xue et al., 2009). There were 19 true hybrids in $\mathrm{ZH}$ population identified by Alf3, FR4, and FR28. The HZ population was all true hybrids identified by FR9, FR25, and FR36. There were a total of 85 true hybrids in 118 individuals of two F1 populations.

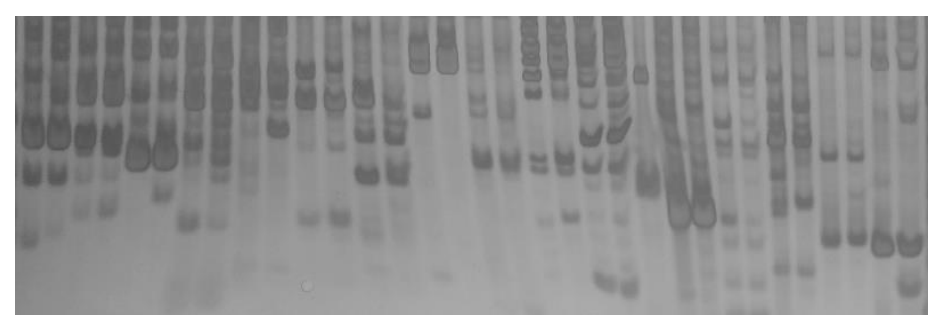

Figure 2. The part results of selection of SRAP and SSR markers in parents Note: Two swim lanes represent a molecular marker; the former swim lane is Medicago ruthenica L. Sojak 'zhilixing' and the latter is wild Medicago ruthenica L..

The rate of true hybrids in $\mathrm{ZH}$ population $(36.54 \%)$ was much lower than that in $\mathrm{HZ}$ population $(100 \%)$. The result was similar to Hong et al. (Hong et al., 2012), who found different rates of true hybrids in reciprocal Arachis Hypogaea L. F1 populations. The corolla color of Medicago ruthenica L. Sojak 'zhilixing' is yellow at front and purplish yellow abaxially, while wild Medicago ruthenica L. has yellow corolla at front and back (Li et al., 2015). Therefore, the internal factors and regulatory mechanisms of the two parent flower may be different, which may contribute to the difference of the true hybrid rates. We will perform further study to verify it. New loci were detected in hybrids, which were different from the parents, indicating that the crossbreeding caused gene recombination (Figure 3). Similar results were observed in Zoysia (Xue et al., 2009) and rice hybrids (Hashemi et al., 2009), which also had abundant variation in hybrids.

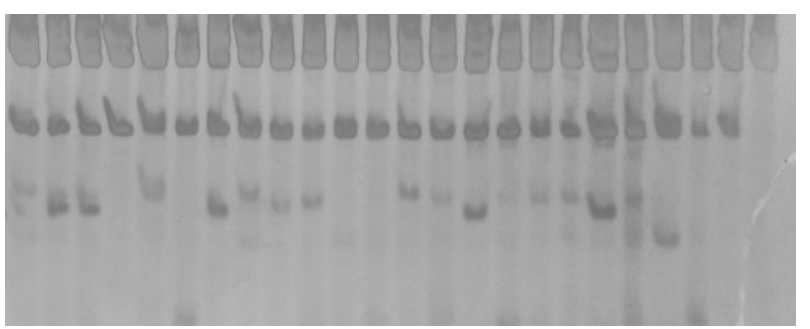

Figure 3. The part results of identification of HZ population by FR9

Note: the last swim lane is wild Medicago ruthenica $\mathrm{L}$.; the penultimate is Medicago ruthenica $\mathrm{L}$. Sojak 'zhilixing'; the rest are $\mathrm{F}_{1}$ hybrids.

\section{Performance of different agronomic traits in hybrids of $\mathrm{ZH}$ population}

The 13 individuals of $\mathrm{ZH}$ population had large variation in many agronomic traits (Table 5). The variation coefficients varied to different degrees ranging from $18.93 \%$ to $45.72 \%$ in 2019 and from $18.53 \%$ to $22.48 \%$ in 2020. There were relatively high variation coefficients of plant above-ground biomass in 2020 and leaf-stem ratio in 2019 , which were $45.72 \%$ and $36.68 \%$, respectively. The number of primary branches also showed a relatively high variation coefficient, which was similar to the results in hybrid progenies of alfalfa cultivars (Wei et al., 2009). The variation of these agronomic traits is significant for improving forage yield. 
Table 5. Performance of different agronomic traits in $\mathrm{F}_{1}$ hybrids of $\mathrm{ZH}$ population

\begin{tabular}{|c|c|c|c|c|c|c|c|c|c|c|c|c|c|c|c|c|c|c|}
\hline \multirow[b]{2}{*}{$\mathrm{F}_{1}$ hybrid } & \multicolumn{3}{|c|}{ Number of primary branches } & \multicolumn{3}{|c|}{ Approximate leaf area $\left(\mathrm{cm}^{2}\right)$} & \multicolumn{2}{|c|}{ Plant type index } & \multicolumn{4}{|c|}{ Leaf-stem ratio } & \multicolumn{3}{|c|}{ Plant absolute height $(\mathrm{cm})$} & \multicolumn{3}{|c|}{ Plant above-ground biomass (g) } \\
\hline & 2019 & 2020 & Mean & 2019 & 2020 & Mean & $2019^{\circ}$ & 2020 & $\mathrm{Me}$ & & 2019 & 2020 & Mean & 2019 & Mean & 2019 & 202 & $0 \quad$ Mean \\
\hline$\overline{\mathrm{ZH} 1}$ & 8 & 17 & 12.5 & 0.98 & 1.31 & 1.145 & 0.19 & 0.22 & 0.205 & 0.96 & 0.53 & 0.745 & 103.5 & 90 & 96.75 & 41.52 & 118 & 79.76 \\
\hline $\mathrm{ZH} 2$ & 8 & 18 & 13 & 1.49 & 1.12 & 1.305 & 0.4 & 0.5 & 0.45 & 0.94 & 0.69 & 0.815 & 79.4 & 62 & 70.7 & 27.35 & 95.81 & 61.58 \\
\hline ZH3 & 8 & 15 & 11.5 & 0.91 & 0.88 & 0.895 & 0.32 & 0.37 & 0.345 & 1.17 & 0.54 & 0.855 & 69.3 & 60 & 64.65 & 13.13 & 86 & 49.565 \\
\hline ZH4 & 8 & 18 & 13 & 0.99 & 0.93 & 0.96 & 0.29 & 0.33 & 0.31 & 0.5 & 0.42 & 0.46 & 91.3 & 80 & 85.65 & 37.06 & 103 & 70.03 \\
\hline ZH5 & 7 & 14 & 10.5 & 1.39 & 1.51 & 1.45 & 0.34 & 0.34 & 0.34 & 0.73 & 0.53 & 0.63 & 87.9 & 62 & 74.95 & 38.82 & 90 & 64.41 \\
\hline ZH6 & 8 & 16 & 12 & 1.21 & 1.81 & 1.51 & 0.48 & 0.4 & 0.44 & 0.51 & 0.66 & 0.585 & 89.2 & 65 & 77.1 & 40.83 & 48.97 & 44.9 \\
\hline ZH7 & 13 & 20 & 16.5 & 1.12 & 1.22 & 1.17 & 0.38 & 0.43 & 0.405 & 0.35 & 0.44 & 0.395 & 111.3 & 94 & 102.65 & 68.84 & 109 & 88.92 \\
\hline ZH8 & 12 & 19 & 15.5 & 1.62 & 1.52 & 1.57 & 0.42 & 0.44 & 0.43 & 0.5 & 0.73 & 0.615 & 78.2 & 64.5 & 71.35 & 41.46 & 90.48 & 65.97 \\
\hline ZH9 & 6 & 13 & 9.5 & 1.52 & 1.38 & 1.45 & 0.35 & 0.4 & 0.375 & 0.81 & 0.64 & 0.725 & 82.9 & 58 & 70.45 & 28.04 & 90 & 59.02 \\
\hline ZH10 & 9 & 19 & 14 & 1.42 & 1.45 & 1.435 & 0.32 & 0.36 & 0.34 & 1.21 & 0.61 & 0.91 & 72.8 & 55 & 63.9 & 26.69 & 84 & 55.345 \\
\hline ZH11 & 6 & 14 & 10 & 1.08 & 1.14 & 1.11 & 0.29 & 0.34 & 0.315 & 1.13 & 0.56 & 0.845 & 66.3 & 50 & 58.15 & 21.98 & 77 & 49.49 \\
\hline ZH12 & 9 & 18 & 13.5 & 1.39 & 1.24 & 1.315 & 0.23 & 0.31 & 0.27 & 0.54 & 0.39 & 0.465 & 104.3 & 90 & 97.15 & 31.78 & 116 & 73.89 \\
\hline ZH13 & 4 & 7 & 5.5 & 1.1 & 1.03 & 1.065 & 0.47 & 0.46 & 0.465 & 0.96 & 0.56 & 0.76 & 33.8 & 52 & 42.9 & 9.51 & 72 & 40.755 \\
\hline Mean & 8.15 & 16 & 12.075 & 1.25 & 1.27 & 1.26 & 0.35 & 0.38 & 0.365 & 0.79 & 0.56 & 0.675 & 82.32 & 67.88 & $\begin{array}{ll}8 & 75.1\end{array}$ & 32.85 & 90.79 & 61.82 \\
\hline $\begin{array}{l}\text { Variation } \\
\text { coefficient (\%) }\end{array}$ & 29.13 & 21.8 & 25.465 & 18.93 & 20.76 & 19.845 & 24.85 & 19.4 & 22.125 & 36.68 & 18.53 & $3 \quad 27.605$ & $5 \quad 24.36$ & 22.48 & $8 \quad 23.42$ & 45.72 & 20.72 & 33.22 \\
\hline
\end{tabular}

Table 6. Heterosis and Heterobeltiosis for different agronomic traits in ZH population

\begin{tabular}{|c|c|c|c|c|c|c|c|c|c|c|c|c|c|c|c|c|c|c|}
\hline \multirow{2}{*}{ Population } & \multicolumn{3}{|c|}{ Number of primary branches } & \multicolumn{3}{|c|}{ Approximate leaf area $\left(\mathrm{cm}^{2}\right)$} & \multicolumn{3}{|c|}{ Plant type index } & \multicolumn{3}{|c|}{ Leaf stem ratio } & \multicolumn{3}{|c|}{ Plant absolute height $(\mathrm{cm})$} & \multicolumn{3}{|c|}{ Plant above-ground biomass $(\mathrm{g})$} \\
\hline & 2019 & 2020 & Mean & 2019 & 2020 & Mean & 2019 & 2020 & Mean & 2019 & 2020 & Mean & 2019 & 2020 & Mean & 2019 & 2020 & Mean \\
\hline $\mathrm{P}_{1}$ & 10.31 & 16.25 & 13.28 & 1.38 & 1.22 & 1.3 & 0.38 & 0.58 & 0.48 & 0.57 & 0.47 & 0.52 & 90.45 & 82.02 & 86.235 & 105.61 & 129.47 & 117.54 \\
\hline $\mathrm{P}_{2}$ & 9.13 & 19 & 14.065 & 0.59 & 0.52 & 0.555 & 0.25 & 0.29 & 0.27 & 0.73 & 0.93 & 0.83 & 65.5 & 44.08 & 54.79 & 37.85 & 31.06 & 34.455 \\
\hline $\mathrm{F}_{1}($ Mean $)$ & 8.15 & 16 & 12.075 & 1.25 & 1.27 & 1.26 & 0.35 & 0.38 & 0.365 & 0.79 & 0.56 & 0.675 & 82.32 & 67.88 & 75.1 & 32.85 & 90.79 & 61.82 \\
\hline $\operatorname{Hm}(\%)$ & -16.12 & -9.22 & -12.67 & 26.74 & 46.18 & 36.46 & 10.9 & -14.15 & -1.625 & 21.95 & -19.72 & 1.115 & 5.58 & 7.67 & 6.625 & -54.21 & 13.11 & -20.55 \\
\hline $\mathrm{Hh}(\%)$ & -20.9 & -15.79 & -18.345 & -9.73 & 4.24 & -2.745 & -7.96 & -35.65 & -21.805 & 8.5 & -39.84 & -15.67 & -8.98 & -17.23 & -13.105 & -68.9 & -29.88 & -49.39 \\
\hline
\end{tabular}


The performance of agronomic traits in the second growth year was greater than that in the first year, which was consistent with the reports of Onat et al. (2017) and Ilker et al. (2018). Plant above-ground biomass and absolute height showed more excellent performance than plant type index and leaf-stem ratio in $\mathrm{ZH} 1$ and $\mathrm{ZH} 12$. However, the plant type index affects forage yield and agricultural management conditions. Improving plant type index could realize high yield at the unit area (Salek and Fakhrvaezi, 2011). Therefore, ZH7 and ZH8 can be used as candidate materials for further research based on their comprehensive performance in 2019 and 2020.

\section{Heterosis analysis of $\mathrm{ZH}$ population}

The $\mathrm{Hm}$ and $\mathrm{Hh}$ were characterized by negative values of 13 individuals in $\mathrm{ZH}$ population. The $\mathrm{Hm}$ was from $54.21 \%$ to $26.74 \%$ in 2019 and from $-19.72 \%$ to $46.18 \%$ in 2020 , while the Hh was from $-68.90 \%$ to $8.50 \%$ in 2019 and from $-39.84 \%$ to $4.24 \%$ in 2020 (Table 6). There was no apparent heterobeltiotic effect, which was an important factor restricting their yield improvement (Zhang et al., 2010). Rajeev et al. (2018) also found the negative heterosis in interspecific hybrids of cotton, which indicated that nonadditive genes dominated in these agronomic traits under genetic control. Many different loci in parents contributed to the positive heterosis in F1 hybrids (Peng et al., 2013; Zhang et al., 2016; Chen et al., 2009). It has been reported that farther relationship the crossing parents had, the better heterosis effect observed in hybrids (Jiang et al., 2017; Zhao et al., 2011). However, the crossing parents both belonged to Medicago ruthenica L. in this study, and they were intraspecific hybridization. Therefore, the close relationship of parents could result in no apparent heterobeltiotic effect in F1 hybrids. Only six specific loci were identified from 13 SSR markers and 36 SRAP markers in parents, and the low ratio of specific loci may be related to their negative heterosis.

\section{ACKNOWLEDGMENT}

This research on molecular identification was developed at Key Laboratory of Grassland Resources of Ministry of Education of China. This research was funded by the Scientific Project of Inner Mongolia, which was named as Research on Stress Resistance Breeding and Cultivating Technology of Native Forage Varieties.

\section{LITERATURE CITED}

Abro, S., M.M. Kandhro, S. Laghari, M.A. Arain and Z.A. Deho. 2009. Combining ability and heterosis for yield contributing traits in upland cotton (Gossypium Hirsutum L.). Pakistan Journal of Botany 41(4):1769-1774.

Bassam, B.J., G. Caetano-Anolles and P.M. Gresshoff. 1991. Fast and sensitive silver staining of DNA in polyacrylamide gels Analytical Biochemistry 196:80-83.

Bianco, C.L., A. Fernández Juan, D. Migliaro, Paola C. and C. Egea-Gilabert. 2011. Identification of F1 hybrids of artichoke by ISSR markers and morphological analysis. Molecular Breeding 27(2):157-170.

Cai, L.Y., F.L. Shi, H.L. Chen, Z.Y. Li, H.Y. Li, C.P. Gao, C.H. Wang and Y.F. Xie. 2013. The heterosis of forage yield of cross combinations with alfalfa males sterile lines. Chinese Journal of Grassland 35(02):24-30.

Campbell, T.A. and Z.L Xia. 2002. Agronomic evaluations of grass and legume forage species collected in the Xinjiang Autonomous Region of the People's Republic of China and Mongolia. Genetic Resources \& Crop Evolution 49(3):295303.

Campbell, T.A., G. Bao and Z.L. Xia. 1997. Agronomic evaluation of Medicago ruthenica collected in Inner Mongolia. Crop Science 37(2):599-604.

Chen, S.L., Y.R. Li, Z.S. Cheng, B.S. Liao, Y. Lei and J.S. Liu. 2009. Heterosis and genetic analysis of oil content in peanut using mixed model of major gene and polygene. Scientia Agricultura Sinica 42(9):3048-3057.

Devran, Z. and O. Baysal. 2012. Genetic characterization of Meloidogyne incognita isolates from Turkey using sequencerelated amplified polymorphism (SRAP). Biologia 67(3):535539.

Du, Z.Y., C.F. Yang, J.M. Chen and Y.H. Guo. 2010. Identification of hybrids in broad-leaved potamogeton species (potamogetonaceae) in china using nuclear and chloroplast dna sequence data. Plant Systematics \& Evolution 287(12):57-63.

Guenni, K., M. Aouadi, K. Chatti and A. Salhi-Hannachi. 2016. Analysis of genetic diversity of Tunisian pistachio (Pistacia vera L.) using sequence-related amplified polymorphism (SRAP) markers. Genetics \& Molecular Research Gmr 15(4):1-15.

Hashemi, S.H., S.A.M. Mirmohammadi-Maibody, G.A. Nematzadeh and A. Arzani. 2009. Identification of rice hybrids using microsatellite and RAPD markers. African Journal of Biotechnology 8(10):2094-2101.

Havelka, M., T. Fujimoto, S. Hagihara, S. Adachi and K. Arai. 2017. Nuclear dna markers for identification of beluga and sterlet sturgeons and their interspecific bester hybrid. Rep. $7(1): 1694$.

Hong, Y.B., S.X. Li, X.Y. Li, F.H. Zhu and X.Q. Liang. 2012. Rapidly identifying hybrids of peanut (Arachis Hypogaea L.) using SSR molecular markers. Molecular Plant Breeding 10(1):110-114.

Ilker, E., K. Mehmet, K. Abdullah, A. Yildirim, G. Ozturk, H. Yildiz and I. Koken. 2018. Adaptation abilities and quality parameters of selected soybean lines under double cropping in the mediterranean region. Turkish Journal of Field Crops 23(1):49-55.

Jiang, X.L., M. Tian, Q. Zhao, T.Y. Song and R.H. Yu. 2017. Relationship between genetic distance, combining ability, and heterosis based SSR marker in sweet corn. Molecular Plant Breeding 15(11):4518-4523.

Liang, X.Y., Y. Ji, S.Q. Bai, L.K. Huang and X.Q. Zhang. 2015. Construction of a genetic map for chicory usingsequencerelated amplified polymorphism markers. Acta Prataculturae Sinica 24(05):153-158.

Li, H.Y., Z.Y. Li, F. Huang, W.G. Shi, J. Li, L. Liu and Y.F. Jie. 2015. Analysis of flower character variation of Medicago ruthenica in Inner Mongolia. Journal of Plant Genetic Resources 16(6):1223-1228.

Li, H.Y., Z.Y. Li, W.G. Shi, L.Y. Cai and J.P. Zhang. 2012. The genetic diversity of three ecological Medicago ruthenica germplasms revealed by ISSR and SSR. Acta Prataculturae Sinica 21(05):107-113.

Liu, Y.J., J.C. You, M. Zhang, J. Hong, M.L. Zhang, H.J. Zhao and H. Chen. 2015. Alfalfa cultivars which are suitable for planting in the alpine region of hulun buir. Grassland and Prataculture 27(02):49-52. 
Liu, Z., Z.F. Wang, H. Geng, H.Z. Yu and A.K. Xu. 2009. The characteristics of drought resistance of 15 alfalfa varieties. Journal of Anhui Agricultural Sciences 37(35):17442- 17444.

Li, Y.L. 2007. Experiment of adaptability of planting Melilotoides ruthenicus (L.) cv 'Zhili' in Gangcha. Auhui Agricultural Science Bulletin 13(17):132-133.

Ma, J.Q., Q.H. Yuan, Y. Wang and L.H. Miao. 2017. Evaluation of the resistance of alfalfa germplasm to Colletotrichum linicola. Acta Agrestia Sinica 25(03):604-611.

Onat, B., H. Bakal, L. Gulluoglu and H. Arioglu. 2017. The effects of row spacing and plant density on yield and yield components of peanut grown as a double crop in mediterranean environment in turkey. Turkish Journal of Field Crops 22(1):71-80.

Patel, N.A., B.N. Patel, J.P. Bhatt and J.A. Patel. 2012. Heterosis and combining ability for seed cotton yield and component traits in inter specific cotton hybrids (Gossypium hirsutum L. $\mathrm{x}$ Gossypium barbadense L.). Madras Agricultural Journal 99(10-12):649-656.

Peng, H., F.D. Chen, W.M. Fang, J.F. Jiang, S.M. Chen, Z.Y. Guan and Y. Liao. 2013. Heterosis and mixed genetic analysis of branch traits of cut chrysanthemum. Acta Horticulturae Sinica 40(7):1327-1336.

Qi, L., W.Q. Wang, Z.W. Zhang, J.Q. Ye and K.J. Li. 2010. DNA fingerprinting analysis of 18 cassava varieties using sequencerelated amplified polymorphism markers. Acta Agronomica Sinica 36(10):1642-1648.

Rajeev, S., S.S. Patil, S.M. Manjula, K.J. Pranesh and H.G. Kencharaddi. 2018. Studies on heterosis in cotton interspecific heterotic group hybrids (G.hirsutum X G.barbadense) for seed cotton yield and its components. International Journal of Current Microbiology \& Applied Sciences 7(10):3437-3451.

Salek Zamani, A. and A.R. FakhrVaezi. 2011. Effect of row spacing and seeding rate on forage yield local alfalfa, c.v. Gara Yonjeh (Medicago sativa). Journal of Crop and Weed Ecophysiology (16):72-82.

Saxena, R.K., K. Saxena and R.K. Varshney. 2010. Application of SSR markers for molecular characterization of hybrid parents and purity assessment of ICPH 2438 hybrid of pigeonpea [Cajanus cajan(L.) Millspaugh]. Molecular Breeding 26(2):371-380.

Shi, W.F., Z.Y. Li, H.Y. Li, C.G. Zhao, X.Y. Li and L. Liu. 2009. Morphological diversity of wilding population in Medicago ruthenica from different origin. Acta Botanica BorealiOccidentalia Sinica 29(5):0867-0873.

Shu, Y.J., W. Li, J.Y. Zhao, Y. Liu and C.H. Guo. 2018. Transcriptome sequencing and expression profiling of genes involved in the response to abiotic stress in Medicago ruthenica. Genetics and Molecular Biology 41(3):638-648.

Talebi, M., Z. Hajiahmadi and M. Rahimmalek. 2011. Genetic diversity and population structure of four Iranian alfalfa populations revealed by sequence-related amplified polymorphism (SRAP) markers. Journal of Crop Science and Biotechnology 14(3):173-178.

Wang, J., J.C. Du, Z.L. Wang, J.Y. Liu and Q.F. Li. 2016. Genetic diversity analysis of 36 alfalfa accessions based on SSR markers. Chinese Journal of Grassland 38(02):20-25.

Wei, W., Y.F. Bi and F.X. Zhang. 2009. Analysis of character variation of geographical distant hybridization progenies among alfalfa cultivars. Grassland and Turf 2009(06):1-4.

Wu, Y.T.N., F.L. Shi, X.L. Xue, F.L. Shi and N. Cui. 2015. Correlation analysis of SSR genetic distance and heterosis on alfalfa. Journal of Plant Genetic Resources 16(06):1237-1244.

Xue, D.D., H.L. Guo, Y.Q. Zheng, X. Chen and J.X. Liu. 2009. Hybrid identification of progenies of Zoysia crosses by SRAP marker. Acta Prataculturae Sinica 18(1):72-79.
Xue, X.L., F.L. Shi, Y.T.N. Wu, M. Xiong and F.L. Shi. 2015. Analysis of heterosis and combining ability of 10 yield traits of hybrid combinations of alfalfa. Prataculture \& Animal Husbandry ?(03):14-17.

Zhang, B.Q., S. Zhou, C.F. Yang, Y.X. Huang, H. Zhou, T. Luo, W.X. Duan, Y.C. Deng, Y.G. Li and G.M. Zhang. 2016. Biomass and root characters of intergeneric hybrid Erianthus arundinaceus $\times$ Saccharum spontaneum and its progeny. Journal of China Agricultural University 21(4):18-25.

Zhang, H.G., X.W. Kong, Z.B. Zhu, S.Z. Tang, C.D. Yi and M.H. Gu. 2010. Analysis of characteristics and heterosis of threeline parents in hybrid Japonica rice. Acta Agronomica Sinica 36(5):801-809.

Zhao, J., X.D. Zhu, Q.Q. Yan, Q.M. Zhao, G.X. Cui, L.J. Peng and M. Xiao. 2011. Analysis of heterosis in yield and agronomic character of hybrid rice. Chinese Agricultural Science Bulletin 27(15):26-33.

Zheng, Y., S. Xu, J. Liu, Y. Zhao and J.X. Liu. 2017. Genetic diversity and population structure of Chinese natural bermudagrass [Cynodon dactylon (L.) Pers.] germplasm based on SRAP markers. PLoS ONE 12(5):e0177508. 